\title{
Analysis of Climate change from high elevation sites of North West Himalaya based on tree ring data.
}

\author{
Santosh K Shah ${ }^{1 *}$, Amalava Bhattacharyya ${ }^{1}$ and Vandana Chaudhary ${ }^{2}$
}

1 Birbal Sahni Institute of Palaeobotany, 53, University Road, Lucknow-226 007, India

2 Department of Science \& Technology, New Mehrauli Road, New Delhi- 110 016, India.

* For correspondence, email: santoshk.shah@gmail.com

The analysis of tree-ring data of Siver fir (Abies pindrow [Royale] Spach.) and Himalayan pine (Pinus wallichiana A.B. Jackson) from the sub-alpine forest from Gangotri glacier region, Northwestern Himalayan signifies the importance of AugustSeptember temperature in controlling the growth of these trees. Mean temperature in each year for these two months has been reconstructed from A.D. 1995 up to A.D. 1773 based on ring-width and density data. The calibration model explains $44 \%$ variance in the instrumental data (1902-1987). The reconstructed temperature series shows annual to multiyear fluctuations punctuated with colder and warmer periods amongst which A.D. 1830-1852 and A.D. 1961-1972 is the coldest and warmest period respectively. For this region both Little Ice Age cooling of 19th or warming of 20th centuries are recorded as discrete phenomena intermittent with smaller phases of warming and cooling episodes respectively. In contrary to the recent global warming there is cooling phase since A.D. 1973 in the reconstruction. Sequential change-point analysis has been used for the first in the dendroclimatic studies from this region and the result indicates the major regime shifts over the sites at 1783, 1794, 1805, 1827, 1862, 1873, 1898 and 1971. 